ORNL/LTR-2015/60

\title{
Survey Study of Trunk Materials for Direct ATRP Grafting - M3FT-15OR03100413
}

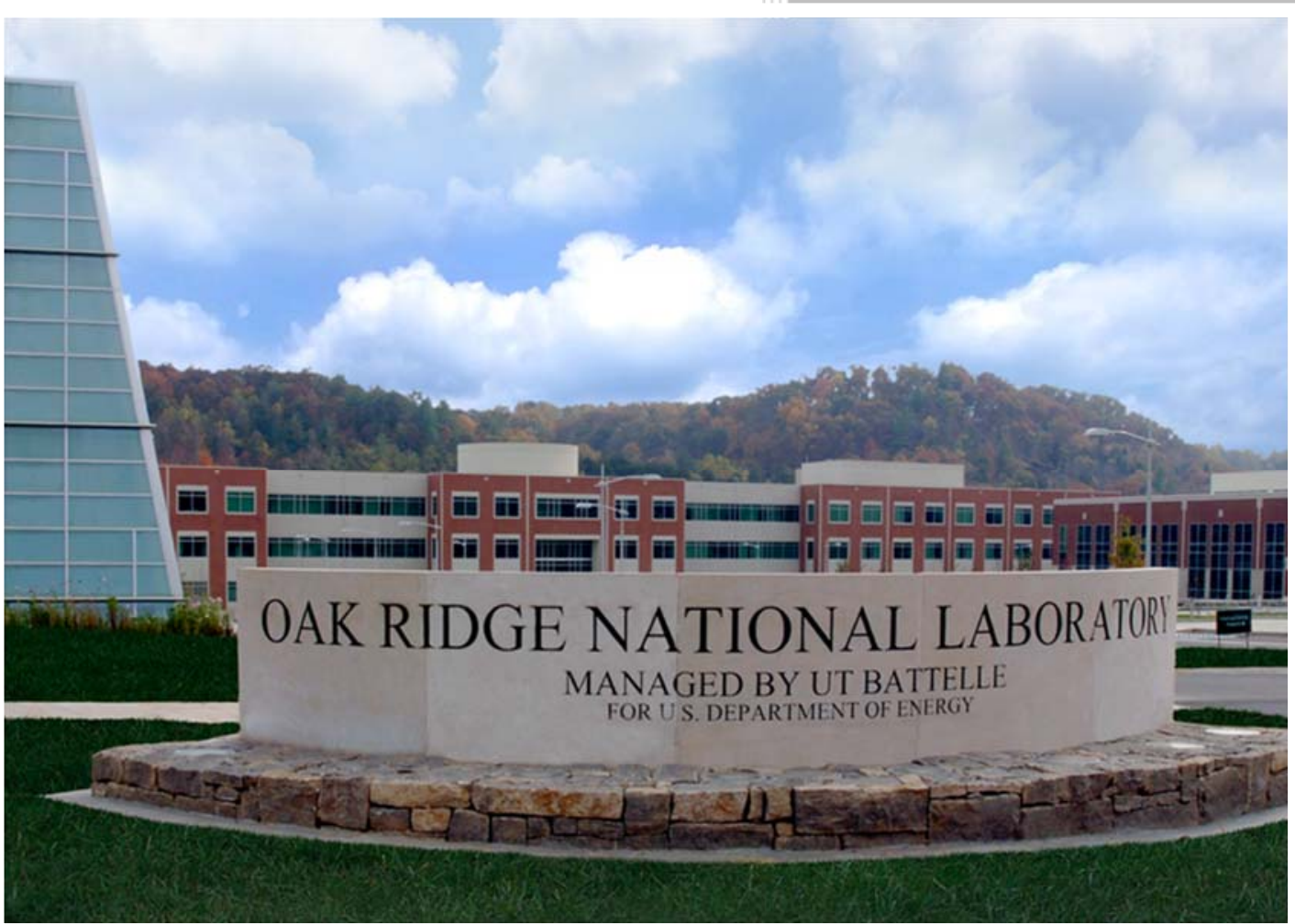

Approved for public release. Distribution is unlimited.
Tomonori Saito

Sabornie Chatterjee

Casey Johnson

Sheng Dai

Suree Brown (Univ. of TN)

September 6, 2017 


\section{DOCUMENT AVAILABILITY}

Reports produced after January 1, 1996, are generally available free via US Department of Energy (DOE) SciTech Connect.

Website http://www.osti.gov/scitech/

Reports produced before January 1, 1996, may be purchased by members of the public from the following source:

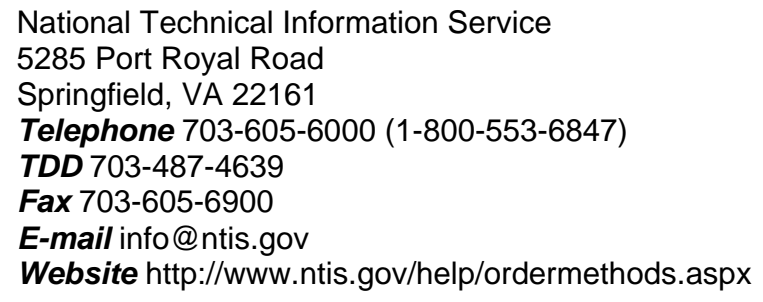

Reports are available to DOE employees, DOE contractors, Energy Technology Data Exchange representatives, and International Nuclear Information System representatives from the following source:

Office of Scientific and Technical Information

PO Box 62

Oak Ridge, TN 37831

Telephone 865-576-8401

Fax 865-576-5728

E-mail reports@osti.gov

Website http://www.osti.gov/contact.html

This report was prepared as an account of work sponsored by an agency of the United States Government. Neither the United States Government nor any agency thereof, nor any of their employees, makes any warranty, express or implied, or assumes any legal liability or responsibility for the accuracy, completeness, or usefulness of any information, apparatus, product, or process disclosed, or represents that its use would not infringe privately owned rights. Reference herein to any specific commercial product, process, or service by trade name, trademark, manufacturer, or otherwise, does not necessarily constitute or imply its endorsement, recommendation, or favoring by the United States Government or any agency thereof. The views and opinions of authors expressed herein do not necessarily state or reflect those of the United States Government or any agency thereof. 
Milestone: M3FT-15OR03100413

Title: Survey Study of Trunk Materials for Direct ATRP Grafting

Authors:

Tomonori Saito, Sabornie Chatterjee, Casey Johnson, Sheng Dai (ORNL)

Suree Brown (University of Tennessee)

\section{Summary}

In a previous study, we demonstrated a new method to prepare polymeric fiber adsorbents via a chemical-grafting method, namely atom-transfer radical polymerization (ATRP), and identified parameters affecting their uranium adsorption capacity. However, ATRP chemical grafting in the previous study still utilized conventional radiation-induced graft polymerization (RIGP) to introduce initiation sites on fibers. Therefore, the objective of the present study was to perform a survey of trunk fiber materials for a direct ATRP chemical-grafting method without RIGP for the preparation of polymer-fiber-based adsorbents for uranium recovery from seawater. We investigated several fibers as shown in Table 1 for a direct ATRP chemical-grafting method, introducing novel chemistry for all these fiber substrates.

Table 1 List of fibers tested for a direct ATRP chemical-grafting and uranium adsorption

\begin{tabular}{|l|l|}
\hline Fiber 1 & Chlorinated polypropylene round fiber (Chlorination followed by ATRP) \\
\hline Fiber 2 & Chlorinated polypropylene hollow-gear fiber (Chlorination followed by ATRP) \\
\hline Fiber 3 & Chlorinated polyethylene hollow-gear fiber (Chlorination followed by ATRP) \\
\hline Fiber 4 & Blend of HDPE and chlorinated polyethylene (Fiber spinning followed by ATRP) \\
\hline Fiber 5 & Polyvinylidene fluoride (PVDF) round fiber (Commercial fiber) \\
\hline Fiber 6 & Polyvinylidene chloride (PVDC) round fiber (Commercial fiber) \\
\hline
\end{tabular}

Novel functionalization (chlorination) on fiber substrates to provide halide functionality (ATRP initiation sites) was successfully performed. These new trunk fibers containing ATRP active sites were chemically grafted via ATRP grafting of acrylonitrile and $t$-butyl acrylate for the first time to the best of our knowledge. The chlorinated hollow-gear polyethylene fiber and chlorinated polypropylene fiber showed the most promising uranium adsorption results among the fibers tested in Table 1 and will be suitable to be used as trunk materials for ATRP for certain comonomers and higher-temperature ATRP, in addition to our standard fiber, i.e., the Rhovyl ${ }^{\mathrm{TM}}$ (PVC-co-CPVC) fiber. Since ATRP grafting is a new technology, no currently existing fibers are made specifically for ATRP grafting. This task was focused on developing a new technology to manufacture fibers suitable for ATRP. However, there are several more candidates of fibers, which may be modified or directly used for ATRP grafting. Also, there are various polymers suitable for ATRP grafting, but not as a fiber form. Fiber spinnability depends on the polymer properties, and experiments to spin fibers for new series of polymers require significant investment. Although this work was successfully completed, we will keep investigating novel fibers for ATRP grafting, seeking improved performance in terms of mechanical properties and uranium adsorption. 


\section{Invention Disclosure related to this Milestone}

- DOE S-NUMBER: S-124,993 INVENTION DISCLOSURE NUMBER: 201403369, T. Saito, S. Brown, S. Dai, "Fast and Efficient Uranium Adsorbents Prepared via Controlled Radical Polymerization.

\section{Background}

The extraction of uranium from seawater presents a very attractive alternative route to obtain uranium for future nuclear fuel needs. However, significant challenges remain for making the extraction of uranium from seawater a commercially viable alternative technology. The biggest challenge for this technology to overcome is the development of adsorbents with increased uranium adsorption capacity and selectivity. In order to achieve increased uranium adsorption capacity, the adsorbent performance has to be optimized, and new technological developments have to be achieved. Technological advances are necessary as this technology requires high selectivity to efficiently extract uranium from such a low-concentration $(\sim 3 \mathrm{ppb})$ solution as seawater, containing several competing ions at higher or similar concentrations.

Over the past 30 years, many efforts had been devoted to this topic, and one of the most successful strategies among them was polymer fiber adsorbents synthesized via RIGP. Over the years, a Japanese team developed polymeric fiber adsorbents, which contained polyethylene or polypropylene as a trunk polymer and amidoximated polyacrylonitrile (PAN) copolymerized with hydrophilic groups (e.g., poly(methacrylic acid)) as a graft chain. The incorporation of hydrophilic groups is essential to allow seawater to access the amidoxime group on the graft chain. Japanese researchers also performed marine tests with stacked unwoven fabrics and braided fibers for different periods of time and at different locations. Their study has established a good foundation to this research field.

Polymeric fiber adsorbents for uranium adsorption have several advantages: 1) already proven to be deployable in seawater, 2) light weight, 3) easy to fabricate to various shapes and lengths. However, polymeric fiber adsorbents prepared solely via conventional RIGP have some limitations such as inability to tune its composition, degree of grafting (d.g.), conformation, and morphology due to its ill-controlled polymerization mechanism. Therefore in our previous study, we investigated a chemical-grafting approach using ATRP to prepare polymeric fiber adsorbents for uranium recovery from seawater. The use of ATRP offers several tunabilities including controllable composition and degree of polymerization (length of graft chains), which can be either increased to a much higher d.g. or controlled to the exact d.g. for the best performance. A hybrid approach of RIGP and ATRP was utilized for adsorbent preparation in our previous study for the demonstration of ATRP grafting.

The present study investigated trunk fiber materials for a direct ATRP chemical-grafting method without RIGP for the preparation of fiber adsorbents for uranium recovery from seawater. The elimination of RIGP makes the fiber-adsorbent preparation method solely via chemical grafting. Since ATRP requires initiation sites, typically substituted halide, the key for the success of direct grafting via ATRP is the incorporation of initiation sites on fiber precursors. Therefore, this study investigated (i) chemistry to incorporate halide-functionalized ATRP initiation sites on various fiber materials and (ii) the effect of ATRP grafting to uranium (U) adsorption capacity. Commercially available fibers already-containing initiation sites were also investigated for ATRP precursor fibers. 


\section{Results and Discussion}

\section{Synthesis of ATRP fiber precursors: Chlorination of polypropylene (PP) fibers}

Adsorbent fibers were prepared in four steps (Fig. 1).

1. Chlorination of PP fibers: Formation of chlorinated PP (CPP)

2. Simultaneous ATRP grafting of a ligand-forming monomer (i.e., acrylonitrile (AN)) and a hydrophilicity-yielding monomer (i.e., tert-butyl acrylate $(t \mathrm{BA}))$ from active chlorine sites on CPP, forming CPP-grafted-poly(acrylonitrile-random-tert-butyl acrylate) (CPP$g-\mathrm{P}(\mathrm{AN}-r-t \mathrm{BA}))$

3. Amidoximation (AO) to convert nitriles on grafted PAN to amidoximes

4. $\mathrm{KOH}$ treatment to hydrolyze $t \mathrm{BA}$ and unreacted $\mathrm{AN}$, if any, on grafted fibers to carboxylates, rendering hydrophilicity in adsorbent fibers

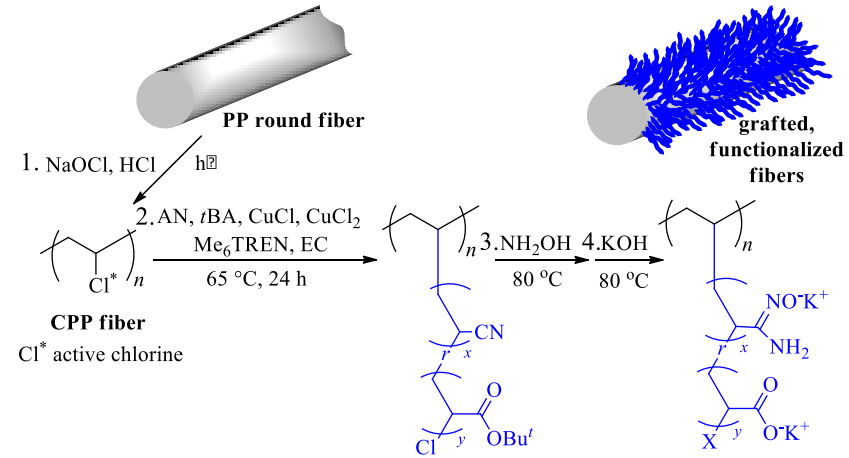

Fig. 1 Scheme representing preparation of adsorbent fibers from PP round fibers.

During chlorination, chlorine gas was generated in-situ from the reaction of $10 \%$ sodium hypochlorite $(\mathrm{NaOCl})$ and $15 \%$ hydrochloric acid $(\mathrm{HCl})$. Under the sunlight or ultraviolet (UV) irradiation (source: Ace mercury arc, model 7825-36, main $\lambda 366 \mathrm{~nm}$ ), chlorine free radicals, capable of homolytically cleaving and substituting $\mathrm{C}-\mathrm{H}$ bonds in PP fiber were generated. The incorporation of chlorine is necessary for ATRP, and the chemistry eliminates the RIGP step. The active, chlorinated sites then acted as ATRP initiation sites for grafting functional polymers in the next step.

In this study, two forms of PP fibers were used: round and hollow-gear (HGPP) fibers. The round PP fiber has the diameter of 20-30 $\mu \mathrm{m}$, measured by scanning electron microscopy. In general, hollow-gear and non-round shaped fibers $(0.24-30 \mu \mathrm{m}$ diameter) have 2-60 times higher surface area than the $20-\mu \mathrm{m}$ diameter round fiber. Despite higher surface area in hollowgear PP fiber, the maximum wt $\% \mathrm{Cl}$ gained after chlorination was only $4.3-5.4 \mathrm{wt} \%$ (condition: UV 1h). Chlorination of HGPP under a more rigorous condition (i.e., UV 1h, followed by UV 2h) resulted in a weight loss of the fiber. The work on HGPP was not further pursued due to its limited amount of chlorination.

In the case of round PP fiber (Fig. 2), chlorination under UV yielded more $w \mathrm{t} \% \mathrm{Cl}$ (gravimetric wt $\%$ ) than chlorination under sunlight. Longer chlorination time also yielded higher $\mathrm{wt} \% \mathrm{Cl}$ in both cases, $\mathrm{UV}$ and sunlight. The maximum $\mathrm{wt} \% \mathrm{Cl}$ obtained was $44.7 \%$. In the case of UV irradiation, two shorter (UV 1h 2x, meaning 1-h chlorination twice) versus one long (UV $2 \mathrm{~h}$ ) chlorination, with the same total time, approximately the same $\mathrm{wt} \%$ of chlorination were obtained in CPP fibers. However, fibers prepared under UV $2 \mathrm{~h}$ were brittle, showing signs of degradation under prolonged UV exposure. Elemental analysis (EA) result of CPP prepared 
under 3-h sunlight $(29.4 \mathrm{wt} \% \mathrm{Cl}$, gravimetrically) showed $19.86 \mathrm{wt} \% \mathrm{Cl}$, corresponding to the empirical formula $\mathrm{CH}_{1.97} \mathrm{Cl}_{0.11}$ (i.e., compared to the empirical formula of PP which is $\mathrm{CH}_{2}$, about 5.5 atom $\%$ of $\mathrm{H}$ were substituted by $\mathrm{Cl}$ ). It is worth mentioning that bromination of round PP fiber with excess liquid $\mathrm{Br}_{2}(20 \mathrm{eq})$ was also tested. However, only $11.6 \mathrm{wt} \% \mathrm{Br}$ was obtained, even after 2-h bromination under UV. The effort on brominated PP was discontinued after a low d.g. (133\%) from ATRP grafting (1000 AN:1000 $t \mathrm{BA}: 1 \mathrm{CuCl}: 1.2 \mathrm{Me}_{6} \mathrm{TREN}: 0.05$ $\mathrm{CuCl}_{2}, 50$ vol\% ethylene carbonate, $\left.65{ }^{\circ} \mathrm{C}, 24 \mathrm{~h}\right)$ and low $\mathrm{U}$ adsorption capacity $(22.8 \mathrm{~g} \mathrm{U} / \mathrm{kg}$ in 250-mL U-spiked test) were obtained from its grafted fiber.

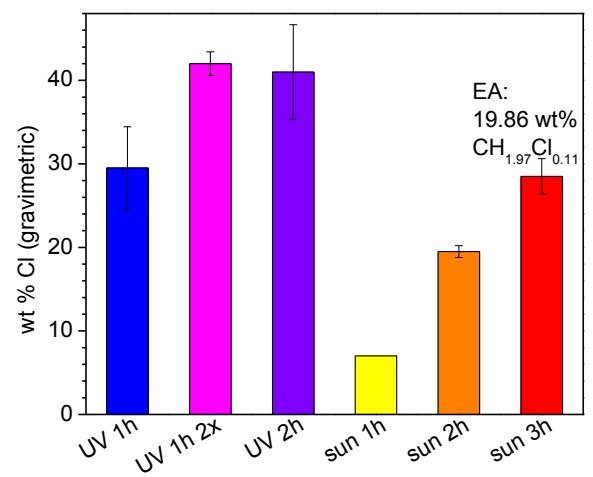

Fig. $2 \mathrm{Wt} \% \mathrm{Cl}$ in round $\mathrm{CPP}$ fibers prepared under different conditions.

${ }^{13} \mathrm{C}$ Cross Polarization/Magic Angle Spinning (CP/MAS) spectra of round CPP fibers revealed that they were mostly composed of non-chlorinated PP structure, showing broad signals centered at $46 \mathrm{ppm}\left(\mathrm{CH}_{2}\right), 26 \mathrm{ppm}(\mathrm{CH})$, and $22 \mathrm{ppm}\left(\mathrm{CH}_{3}\right)\left(\right.$ Fig. 3). The result in ${ }^{13} \mathrm{C} \mathrm{CP} / \mathrm{MAS}$ spectra is in agreement with the limited $w t \% \mathrm{Cl}$ obtained gravimetrically and with the empirical formula calculated from EA. Chlorination on PP was reported to begin at $3^{\circ}$, then $2^{\circ}$, and $1^{\circ}$ carbons, respectively. ${ }^{1}$ In all fibers, a broad signal centered at 75 to $81 \mathrm{ppm}$, ascribed to monochlorinated $4^{\circ}$ carbons (i.e., $-\mathrm{C}\left(\mathrm{CH}_{3}\right) \mathrm{Cl}-$ ), was also observed. Very likely the chlorination occurred on $3^{\circ}$ carbons first, resulting in $-\mathrm{C}\left(\mathrm{CH}_{3}\right) \mathrm{Cl}-$, followed by monochlorination on $2^{\circ}$ carbon, resulting in $-\mathrm{CHCl}-(66 \mathrm{ppm})$. Finally, when another chlorine radical attacked $-\mathrm{CHCl}-$, dichlorinated carbons $\left(-\mathrm{CCl}_{2}-, 105 \mathrm{ppm}\right)$ formed.

In comparison between sunlight and UV-chlorination, UV was found to be more effective in chlorinating $\mathrm{PP}$, consistent with wt $\% \mathrm{Cl}$ results. Under $\mathrm{UV}$ irradiation, signals from $-\mathrm{CCl}_{2}-$ were observed after $2 \mathrm{~h}$. Under sunlight, it took 3 -h chlorination before the $-\mathrm{CCl}_{2}-$ signal was observed (see inset). However, spectra of CPP from UV-chlorination also showed broad signals at more downfield positions, ca. 120 to $140 \mathrm{ppm}$, assignable to terminal vinyl groups, $\mathrm{CH}_{2}=\mathrm{CH}-\mathrm{CHCl}-$, also found in polyvinyl chloride. ${ }^{2}$ These groups plausibly formed during the fiber degradation by chain scission, ${ }^{1}$ especially after a prolonged UV exposure (i.e., $2 \mathrm{~h}$ ). In all conditions studied, no signal from monochlorination of $1^{\circ}$ carbon (i.e., $-\mathrm{CH}_{2} \mathrm{Cl}$ at $50 \mathrm{ppm}$ ), ${ }^{3}$ was observed. The expected order of activity as ATRP initiation sites is as follows: $-\mathrm{CCl}_{2}->$ $-\mathrm{C}\left(\mathrm{CH}_{3}\right) \mathrm{Cl}->-\mathrm{CHCl}->-\mathrm{CH}_{2} \mathrm{Cl}$. 


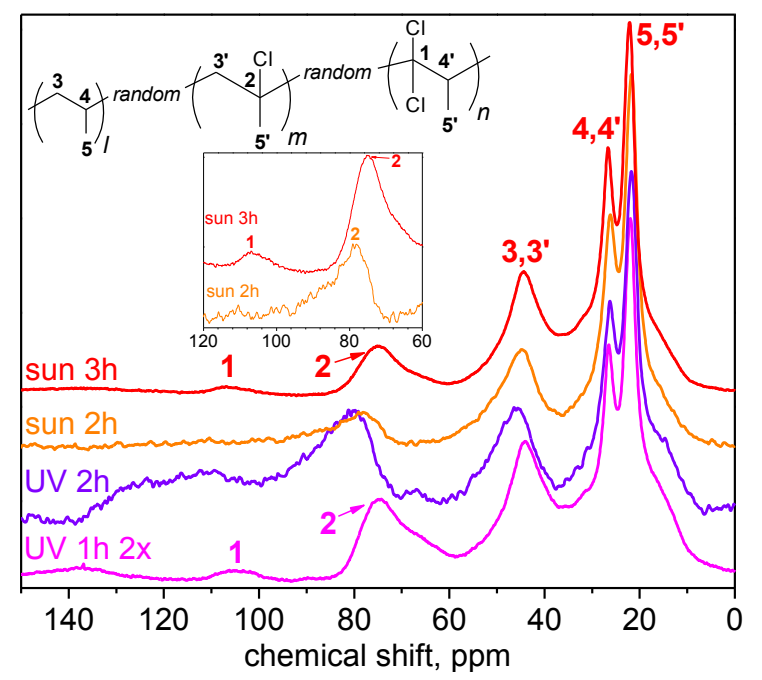

Fig. 3 100-MHz ${ }^{13} \mathrm{C} \mathrm{CP/MAS} \mathrm{spectra} \mathrm{of} \mathrm{round} \mathrm{CPP} \mathrm{fibers} \mathrm{(spinning} \mathrm{speed} 7.5 \mathrm{kHz}$ ). Inset: expansion spectra of sun $2 \mathrm{~h}$ and sun $3 \mathrm{~h}$ spectra. *Numbers on the chemical structure on the top corresponds to numbers on the spectra.

\section{ATRP from round CPP fibers and uranium adsorption results}

All ATRP reactions reported here were performed at $1 \mathrm{CuCl}: 1.2 \mathrm{Me}_{6} \mathrm{TREN}: 0.05 \mathrm{CuCl}_{2}: 1$ $\mathrm{RCl}$ in $50 \mathrm{vol} \%$ ethylene carbonate (EC) at $65^{\circ} \mathrm{C}$ for $24 \mathrm{~h}$ (Table 2). The optimal AN:tBA feed ratio for $U$ adsorption was guided by our earlier results from a similar system, using Rhovyl $^{\mathrm{TM}}$ trunk fiber. Compared between fibers grafted under identical ATRP conditions (i.e., the same $\mathrm{AN}: t \mathrm{BA}: \mathrm{RCl}$ molar ratios), grafting from fibers chlorinated under UV (entries 1-4) yielded lower d.g. than those from fibers chlorinated under sunlight (entries 5-14), regardless of wt $\% \mathrm{Cl}$ in CPP. Among trunk fibers chlorinated under UV, 1-h twice chlorinated fiber (entries 1-2) yielded higher than or comparable d.g. to those from prolonged UV exposure (i.e., 2-h). This is consistent with more extent of decomposition of chlorinated sites under prolonged UV exposure, observed in ${ }^{13} \mathrm{C} \mathrm{CP} / \mathrm{MAS}$ spectra.

Among ATRP grafting from fibers chlorinated under sunlight, 3-h chlorination (entries 8-14) gave higher d.g. than those from 2-h chlorination (entries 5-7). This cannot be explained only by their higher $\mathrm{wt}_{\mathrm{t}} \mathrm{Cl}$, but also by the presence of more active ATRP initiation sites, $-\mathrm{CCl}_{2}-$. While the $-\mathrm{C}\left(\mathrm{CH}_{3}\right) \mathrm{Cl}-$ groups did initiate ATRP, as observed in the case of sun $2 \mathrm{~h}$ $\mathrm{CPP}$, the presence of even a small amount of $-\mathrm{CCl}_{2}-$ in sun $3 \mathrm{~h}$ CPP tripled the d.g.

After ATRP grafting, fibers were amidoximated, then treated with $\mathrm{KOH}$ at $80{ }^{\circ} \mathrm{C}$ for $3 \mathrm{~h}$. Uranium adsorption tests in U-spiked simulated seawater were then performed under the following conditions: $\sim 15 \mathrm{mg}$ adsorbent in $250 \mathrm{~mL}$ or $750 \mathrm{~mL}$ (for better-performed adsorbents) of 5-7 ppm U, $10123 \mathrm{ppm} \mathrm{Na}^{+}, 15529 \mathrm{ppm} \mathrm{Cl}^{-}, 140 \mathrm{ppm} \mathrm{HCO}_{3}{ }^{-}, \mathrm{pH} 8,20-25{ }^{\circ} \mathrm{C}, 24 \mathrm{~h}$. The uranium analysis was performed by ICP-OES at $\lambda_{U} 367.007 \mathrm{~nm}$. Compared between adsorbent fibers prepared under identical ATRP conditions (i.e., the same AN:tBA:RCl), U adsorption capacities in the $250-\mathrm{mL}$ spiked test also followed the same trend as the d.g., increasing in the following order: $\mathrm{UV}<\operatorname{sun} 2 \mathrm{~h}<\operatorname{sun} 3 \mathrm{~h}$. Compared with $\mathrm{U}$ adsorption capacities obtained from identical 250-mL U-spiked test on conventional adsorbents, including fiber adsorbent provided by the Japan Atomic Energy Agency (JAEA) prepared by RIGP ( 20 g/kg), METSORB 16/60 
$(25.2 \mathrm{~g} / \mathrm{kg})$, METSORB STP $(12.3 \mathrm{~g} / \mathrm{kg})$, METSORB HMRP $50(46.3 \mathrm{~g} / \mathrm{kg})$, and Dyna Aqua $(21.2 \mathrm{~g} / \mathrm{kg})$, these fiber adsorbents prepared from ATRP gave comparable or higher U adsorption capacities.

Table 2 Simultaneous ATRP grafting of AN and $t$ BA from round CPP fibers and U-spiked test

\begin{tabular}{|c|c|c|c|c|c|c|c|c|c|c|c|}
\hline \multirow{2}{*}{ no. } & \multirow{2}{*}{$\begin{array}{l}\text { chlorination } \\
\text { conditions } \\
\text { (round CPP } \\
\text { fiber) }\end{array}$} & \multirow{2}{*}{$\begin{array}{c}\mathrm{wt} \% \\
\mathrm{Cl}\end{array}$} & \multicolumn{2}{|c|}{ feed ratio } & \multirow{2}{*}{$\begin{array}{c}\text { mole } \\
\text { fraction } \\
\text { AN } \\
\text { (feed) } \\
\end{array}$} & \multirow{2}{*}{$\begin{array}{l}\text { mole } \\
\text { fraction } \\
\text { PAN } \\
\text { (EA) } \\
\end{array}$} & \multirow{2}{*}{$\begin{array}{c}\text { d.g., } \\
\%\end{array}$} & \multicolumn{2}{|c|}{$\begin{array}{l}250-\mathrm{mL} \text { U- } \\
\text { spiked test }\end{array}$} & \multicolumn{2}{|c|}{$\begin{array}{l}750-\mathrm{mL} \mathrm{U}- \\
\text { spiked test }\end{array}$} \\
\hline & & & AN & $t \mathrm{BA}$ & & & & $\mathrm{g} / \mathrm{kg}$ & $\begin{array}{r}\% \\
\text { ads. }\end{array}$ & $\mathrm{g} / \mathrm{kg}$ & $\begin{array}{r}\% \\
\text { ads. }\end{array}$ \\
\hline 1 & UV 1 h $2 x$ & 40.7 & 200 & 160 & 0.556 & & $\begin{array}{c}125- \\
255\end{array}$ & 30.7 & 34.7 & & \\
\hline 2 & UV 1 h $2 x$ & 40.7 & 500 & 400 & 0.556 & & 49 & 32.6 & 33.7 & & \\
\hline 3 & UV $2 \mathrm{~h}$ & 44.7 & 200 & 160 & 0.556 & & 55 & 45.6 & 50.16 & & \\
\hline 4 & UV $2 \mathrm{~h}$ & 44.7 & 500 & 400 & 0.556 & & 66 & 19.8 & 20.6 & & \\
\hline 5 & $\operatorname{sun} 2 \mathrm{~h}$ & 20.0 & 200 & 160 & 0.556 & & 127 & 40.1 & 43.8 & & \\
\hline 6 & sun & 19.3 & 500 & 400 & 0.556 & 0.796 & 439 & 72.6 & 65.4 & 86.5 & 25.2 \\
\hline 7 & $\operatorname{sun} 2 \mathrm{~h}$ & 19.3 & 1000 & 100 & 0.909 & & 231 & 23.0 & 26.9 & & \\
\hline 8 & $\operatorname{sun} 3 \mathrm{~h}$ & 29.4 & 500 & 0 & 1.00 & & 425 & & & 83.2 & 24.0 \\
\hline 9 & sun $3 h$ & 29.4 & 500 & 100 & 0.833 & & 477 & & & 111.9 & 33.9 \\
\hline 10 & $\operatorname{sun} 3 \mathrm{~h}$ & 29.4 & 500 & 200 & 0.714 & 0.838 & 822 & & & 132.9 & 40.8 \\
\hline 11 & $\operatorname{sun} 3 \mathrm{~h}$ & 29.4 & 500 & 300 & 0.625 & 0.759 & 1000 & & & 96.9 & 30.3 \\
\hline 12 & $\operatorname{sun} 3 \mathrm{~h}$ & 29.4 & 500 & 400 & 0.556 & 0.734 & 1255 & 74.8 & 76.8 & 146.6 & 45.5 \\
\hline 13 & sun $3 h$ & 29.4 & 500 & 500 & 0.500 & & 1508 & 70.7 & 71.1 & 99.9 & 31.8 \\
\hline 14 & sun $3 h$ & 29.4 & 500 & 600 & 0.455 & & 2570 & 84.3 & 81.4 & 102.5 & 33.3 \\
\hline
\end{tabular}

Fiber adsorbents with high $\mathrm{U}$ adsorption capacities in the 250-mL spiked test were selected for the $750-\mathrm{mL}$ spiked test. From the $750-\mathrm{mL}$ test, the fiber grafted from sun-2h CPP (entry 6) did not show as high U adsorption capacity as the fiber grafted under identical ATRP conditions from the sun-3h CPP fiber (entry 12). This further confirmed the result from the 250$\mathrm{mL}$ spiked test. Among grafted fibers prepared from sun-3h CPP fibers, AN:tBA molar ratios drastically affected $U$ adsorption capacities and the optimal AN: $t$ BA ratio in the feed was found to be 500:400 (entry 12). At lower or higher AN: $t \mathrm{BA}$ ratios, adsorption capacities dropped significantly. The effect of the composition ratio of $\mathrm{AN}: t \mathrm{BA}$ to $\mathrm{U}$ adsorption capacities is consistent with our previous work. ${ }^{4}$

Four adsorbent fibers with relatively high $\mathrm{U}$ adsorption capacities were sent for elemental analysis at Galbraith Laboratories. Mole fractions of PAN calculated from EA results were significantly higher than mole fractions of AN in their feeds, indicating efficient polymerization and reflecting the higher reactivity ratio of AN than that of tBA, consistent with our previous work. ${ }^{4}$ The mole fraction of PAN optimized for highest $\mathrm{U}$ adsorption capacity in grafted fibers from CPP was 0.734 , very close to that of grafted fibers from Rhovyl ${ }^{\mathrm{TM}}$ fiber that we studied (0.738).

${ }^{13} \mathrm{C} \mathrm{CP} / \mathrm{MAS}$ spectra of representative fibers (Table 1 entry 13, and corresponding AO and $\mathrm{KOH}$ products) are shown in Fig. 4. In the grafted fiber (trace $a$ ) signals from $-\mathrm{COOBu}^{t}$ in $\mathrm{P}(t \mathrm{BA})(173 \mathrm{ppm}),-\mathrm{CN}$ in PAN $(120 \mathrm{ppm}), 4^{\circ}$ carbon in $\mathrm{P}(\mathrm{BA})(82 \mathrm{ppm})$, methylene carbons in grafted chains and in CPP (42 ppm), and methyl carbons in $\mathrm{P}(t \mathrm{BA})$, overlapping with methine and methyl carbons in CPP (29 ppm) were observed. After AO (trace $b$ ), a new signal from 
amidoxime, $-\left(\mathrm{NH}_{2}\right) \underline{\mathrm{C}}=\mathrm{NOH}$, appeared at $149 \mathrm{ppm}$, and the $-\mathrm{CN}$ signal disappeared, indicating the completion of $\mathrm{AO}$ reaction. Other signals, except that of methyl and methine carbons, were also broader, indicating a more heterogeneous environment in the fiber after AO. After $\mathrm{KOH}$ treatment (trace $c)$, two new signals, carboxylate $(184 \mathrm{ppm})$ and amidoxime $(160 \mathrm{ppm})$, were observed. The carboxylate signal confirmed that the hydrolysis of $\mathrm{P}(t \mathrm{BA})$ took place, although it was incomplete. Signals from $4^{\circ}$ carbon $(82 \mathrm{ppm})$ and carbonyl $(176 \mathrm{ppm})$ in $\mathrm{P}(\mathrm{BAA})$ were still observed. The new amidoxime signal very likely reflected newly formed hydrophilic surroundings, i.e., these poly(amidoximes) were adjacent to hydrolyzed $\mathrm{P}(t \mathrm{BA})$ in grafted polymer chains.

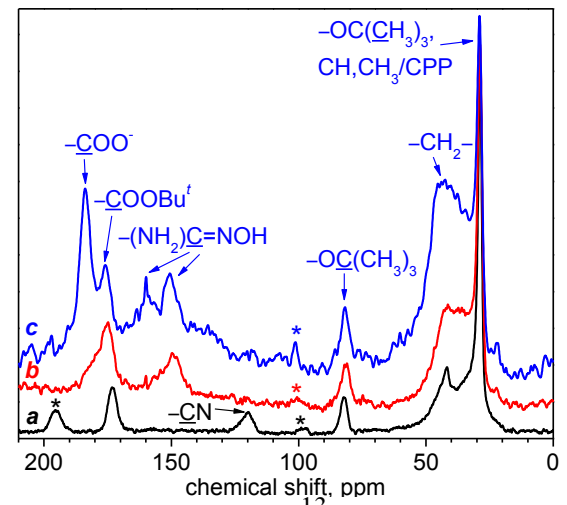

Fig. 4 100-MHz ${ }^{13} \mathrm{C} \mathrm{CP} / \mathrm{MAS}$ spectra of $\boldsymbol{a}$ ) grafted (Table 1, entry 13), b) amidoximated, and $\boldsymbol{c}$ ) $\mathrm{KOH}$ treated fibers (* denotes spinning sideband, spinning speed $7.5 \mathrm{kHz}$ ).

Fiber adsorbents were also characterized using an Excalibur FT-IR with an MVP-Pro ATR Accessory (Fig. 5). As expected, grafted fiber showed $\mathrm{C} \equiv \mathrm{N}\left(2243 \mathrm{~cm}^{-1}\right)$ and $\mathrm{C}=\mathrm{O}$ stretches $\left(1719 \mathrm{~cm}^{-1}\right)$ from grafted PAN and grafted $\mathrm{P}(\mathrm{tBA})$, respectively. After $\mathrm{AO}$, the $\mathrm{C} \equiv \mathrm{N}$ stretch disappeared, indicating the completion of $\mathrm{AO}$ reaction, and new bands assigned to imine $-\mathrm{C}=\mathrm{N}-$ $\left(1640 \mathrm{~cm}^{-1}\right)$ and $\mathrm{N}-\mathrm{O}\left(923 \mathrm{~cm}^{-1}\right)$ stretches of the oxime were observed. Also, the $\mathrm{C}=\mathrm{O}$ stretch shifted to $1701 \mathrm{~cm}^{-1}$, plausibly reflecting the change in its adjacent groups in polymer grafted chains which were converted from nitriles to amidoximes. After $\mathrm{KOH}$ treatment, a new band ascribed to $\mathrm{C}=\mathrm{O}$ in carboxylate $\left(1555 \mathrm{~cm}^{-1}\right)$ was observed, confirming the result from ${ }^{13} \mathrm{C}$ $\mathrm{CP} / \mathrm{MAS}$ that the hydrolysis of $\mathrm{P}(t \mathrm{BA})$ occurred. The $\mathrm{C}=\mathrm{O}$ stretch $\left(1701 \mathrm{~cm}^{-1}\right)$ in $\mathrm{P}(t \mathrm{BA})$ still remained, indicating some of $\mathrm{P}(t \mathrm{BA})$ was not hydrolyzed, which agrees well with the result in ${ }^{13} \mathrm{C} \mathrm{CP} /$ MAS. More importantly, $-\mathrm{C}=\mathrm{N}-\left(1645 \mathrm{~cm}^{-1}\right)$ and $\mathrm{N}-\mathrm{O}\left(922 \mathrm{~cm}^{-1}\right)$ stretches of the oxime were still observed. The preservation of $\mathrm{N}-\mathrm{O}$ stretch during $\mathrm{KOH}$ is critical as this bond has been reported to chelate the uranyl ion in the $\eta^{2}$ fashion, which may lead to selective binding. 


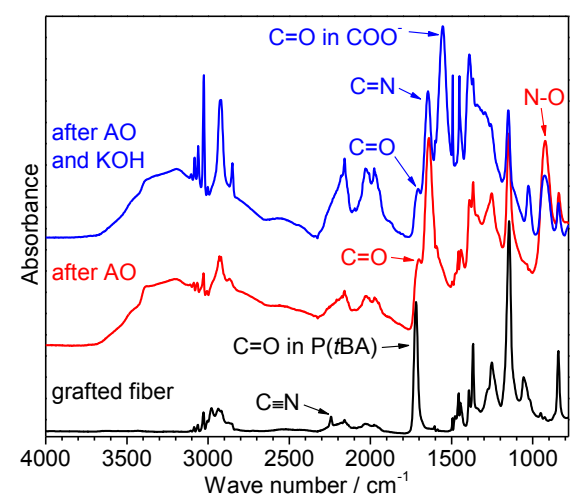

Fig. 5 FT-IR spectra of grafted fiber (Table 1, entry 13) and corresponding fibers after AO and $\mathrm{KOH}$ treatment.

\section{ATRP from chlorinated hollow-gear PE fibers and uranium adsorption results}

In a similar manner to the hollow-gear PP fiber, hollow-gear PE fiber (fiber \#17) was used in chlorination due to its much higher surface area than round fibers. Under UV irradiation and in the presence of in-situ generated $\mathrm{Cl}_{2}$, hollow-gear-shaped, chlorinated polyethylene (HGCPE) fibers were produced. $\mathrm{Wt} \% \mathrm{Cl}$ from 1-h and 2-h chlorination under UV were plotted along with results from round CPP fibers (reported earlier) for comparison (Fig. 6). Overall, wt\% $\mathrm{Cl}$ in HGCPE was found to be of the same magnitude with those in round CPP fibers. Effective chlorination of HGPE occurred rapidly, within $1 \mathrm{~h}$, yielding $33.7 \mathrm{wt} \% \mathrm{Cl}$ (gravimetrically). From elemental analysis (EA) of HGCPE from 1-h UV chlorination, $31.60 \mathrm{wt} \% \mathrm{Cl}$, corresponding to the empirical formula of $\mathrm{CH}_{0.79} \mathrm{Cl}_{0.19}$, confirmed the $\mathrm{wt} \% \mathrm{Cl}$ obtained gravimetrically. Unlike $\mathrm{CPP}$, prolonged chlorination, did not increase the wt $\% \mathrm{Cl}$, very likely due to side reactions (e.g., chain scission).

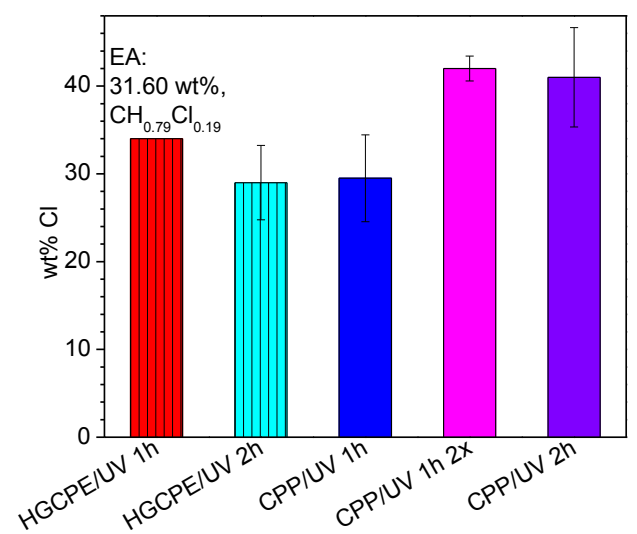

Fig. $6 \mathrm{Wt} \% \mathrm{Cl}$ in hollow-geared-shaped CPE (HGCPE), compared with round CPP fibers.

HGCPE fibers were characterized by ${ }^{13} \mathrm{C} \mathrm{CP} / \mathrm{MAS}$ (Fig. 7). The UV $1 \mathrm{~h}$ HGCPE showed signals from PE (33 ppm), monochlorinated (66 ppm), and dichlorinated (98 ppm) carbons. The UV 2h HGCPE showed mainly the PE and monochlorinated carbons. The amount of dichlorinated carbon was minimal, if any, and its signal, expected at $98 \mathrm{ppm}$, could not be clearly distinguished from the spectrum's baseline. This is consistent with the lower wt $\% \mathrm{Cl}$ obtained 
after 2-h chlorination, compared to 1-h chlorination. The disappearance of dichlorinated carbon after 2-h chlorination was very likely due to its decomposition under a prolonged UV exposure.

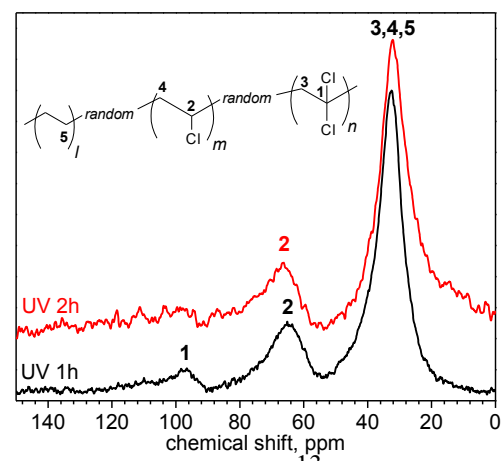

Fig. 7 100-MHz ${ }^{13} \mathrm{C} \mathrm{CP} / \mathrm{MAS}$ spectra of HGCPE fibers (spinning speed $7.5 \mathrm{kHz}$ ).

Since HGCPE prepared by 1 -h chlorination had higher $\mathrm{wt}^{\mathrm{O}} \mathrm{Cl}$ than that from 2-h chlorination, it was used as an ATRP initiator for simultaneous grafting of AN and $t$ BA. ATRP reactions were performed using $1 \mathrm{CuCl}: 1.2 \mathrm{Me}_{6}$ TREN:0.05 $\mathrm{CuCl}_{2}: 1 \mathrm{RCl}$ in $50 \mathrm{vol} \%$ solvent at $65{ }^{\circ} \mathrm{C}$ for $24 \mathrm{~h}$ (Table 3). The d.g. obtained, though reasonably high, were not as high as those from round CPP fibers. U adsorption capacities were also lower, in agreement with their lower d.g., than those from round CPP fibers.

Table 3 Simultaneous ATRP grafting of AN and $t$ BA from HGCPE fibers and U-spiked test

\begin{tabular}{|c|c|c|c|c|c|c|c|}
\hline \multirow[t]{2}{*}{$\begin{array}{l}\text { chlorination conditions } \\
\text { (HGCPE fiber) }\end{array}$} & \multirow[t]{2}{*}{$\begin{array}{c}\mathrm{wt} \% \\
\mathrm{Cl}\end{array}$} & \multirow[t]{2}{*}{ solvent } & \multirow{2}{*}{$\begin{array}{c}\begin{array}{c}\text { feed } \\
\text { ratio }\end{array} \\
\mathrm{AN} t \mathrm{BA} \\
\end{array}$} & \multirow[t]{2}{*}{$\begin{array}{l}\text { mole fraction AN } \\
\text { (feed) }\end{array}$} & \multirow[t]{2}{*}{$\begin{array}{c}\text { d.g., } \\
\%\end{array}$} & \multicolumn{2}{|c|}{$\begin{array}{l}\text { 750-mL U- } \\
\text { spiked test }\end{array}$} \\
\hline & & & & & & $\mathrm{g} / \mathrm{kg}$ & $\%$ ads. \\
\hline UV 1h & 33.7 & $\mathrm{EC}$ & 492246 & 0.667 & 545 & 80.8 & 22.9 \\
\hline UV $1 \mathrm{~h}$ & 33.7 & DMSO & 492310 & 0.613 & 367 & 64.6 & 18.5 \\
\hline
\end{tabular}

Overall, even though HGPE possesses higher surface area than does round PP fiber, the $\mathrm{wt} \% \mathrm{Cl}$ in HGCPE was found to be limited, not unlike the round CPP. The d.g. and U adsorption capacities of grafted fibers from HGCPE were lower than those from round CPP. The higher surface area of HGCPE did not yield the expected advantage, maybe due to inaccessible surface area and non-optimized conformation.

\section{ATRP from commercial PVDF and PVDC fibers and uranium adsorption results}

Polyvinylidene fluoride (PVDF) and polyvinylidene chloride (PVDC) are commercially available fibers and they have low solubilities in most solvents, including DMSO and EC, even at elevated temperatures, thereby, maintaining their morphologies (e.g., fiber form) during ATRP grafting. Also, their ATRP can be conducted in a more variety of monomers than does Rhovyl ${ }^{\mathrm{TM}}$ fiber that we have been using. As a survey study, one type of PVDF and three types of PVDC fibers, varying in shape and diameter, were used for simultaneous ATRP grafting of AN and $t$ BA at $65{ }^{\circ} \mathrm{C}$ and $24 \mathrm{~h}$. Table 4 shows the details of trunk fibers along with ATRP results and U adsorption capacities from 750-mL spiked tests. As expected, PVDF fiber showed no activity as an ATRP initiator and no grafting occurred. On the other hand, PVDC fibers showed extremely high activity in ATRP, yielding unprecedentedly high d.g. At lower amounts of $\mathrm{CuCl}$ catalyst 
and monomers, less d.g. was obtained. However, grafted fibers were still easily broken off from trunk PVDC fibers, even at a controlled and very low d.g. (i.e., 43\%). Due to the loss of functional groups in grafted chains, $U$ adsorption capacities were not as high as expected from high d.g. adsorbent fibers.

Table 4 ATRP grafting of AN and $t$ BA from PVDF and PVDC fibers and U-spiked test

\begin{tabular}{|c|c|c|c|c|c|c|}
\hline \multirow{2}{*}{ Trunk fiber } & \multirow{2}{*}{$\mathrm{CuCl}: \mathrm{Me}_{6} \mathrm{TREN}: \mathrm{CuCl}_{2}: \mathrm{RCl}$} & \multirow{2}{*}{$\begin{array}{c}\begin{array}{c}\text { feed } \\
\text { ratio }\end{array} \\
\text { AN } t \mathrm{BA}\end{array}$} & \multirow{2}{*}{$\begin{array}{c}\text { mole } \\
\text { fraction } \\
\text { AN (feed) }\end{array}$} & \multirow{2}{*}{ d.g., $\%$} & \multicolumn{2}{|c|}{$\begin{array}{l}750-\mathrm{mL} \mathrm{U}- \\
\text { spiked test }\end{array}$} \\
\hline & & & & & $\underset{U}{\mathrm{U} / \mathrm{kg}}$ & $\begin{array}{c}\% \\
\text { ads. }\end{array}$ \\
\hline $\begin{array}{l}\text { PVDF: Swicofil }{ }^{\mathrm{TM}} \text {, } \\
\text { diam. } 28.6 \mu \mathrm{m}, 1100 \\
\text { dtex }(9.1 \mathrm{~m} / \mathrm{g})\end{array}$ & $\begin{array}{c}0.66: 0.78: 0.03: 1 \\
\text { in } 50 \mathrm{vol} \% \text { DMSO }\end{array}$ & 330166 & 0.666 & 0 & $\mathrm{~N} / \mathrm{A}$ & $\mathrm{N} / \mathrm{A}$ \\
\hline $\begin{array}{l}\text { PVDC, Mitsui }{ }^{\mathrm{TM}}, 40 \\
\mu \mathrm{m} \text {, staple, } 15 \text { dtex x } 15 \\
\mathrm{~cm}\end{array}$ & $\begin{array}{c}1: 1.2: 0.05: 1 \\
\text { in } 50 \mathrm{vol} \% \mathrm{EC}\end{array}$ & 501254 & 0.664 & $\begin{array}{l}\text { 3366; } \\
\text { brown } \\
\text { powder }\end{array}$ & 63.7 & 19.2 \\
\hline $\begin{array}{l}\text { PVDC (Mitsui }{ }^{\mathrm{TM}}, 40 \\
\mu \mathrm{m}, \text { staple, } 15 \text { dtex x } 15 \\
\mathrm{~cm})\end{array}$ & $\begin{array}{l}0.5: 0.6: 0.025: 1 \\
\text { in } 50 \mathrm{vol} \% \mathrm{EC}\end{array}$ & 251127 & 0.664 & $\begin{array}{l}\text { 43; fiber } \\
\text { easily } \\
\text { broken }\end{array}$ & 51.5 & 14.2 \\
\hline $\begin{array}{l}\text { PVDC (Mitsui }{ }^{\mathrm{TM}}, 90 \\
\mu \mathrm{m}, \text { hollow, black, } 800 \\
\text { den }(889 \text { dtex, } 11.2 \mathrm{Nm})\end{array}$ & $\begin{array}{c}1: 1.2: 0.05: 1 \\
\text { in } 50 \mathrm{vol} \% \mathrm{EC}\end{array}$ & 501254 & 0.664 & $\begin{array}{l}2517 \\
\text { brown } \\
\text { pieces }\end{array}$ & 85.2 & 20.7 \\
\hline $\begin{array}{l}\text { PVDC (Swicofil }{ }^{\mathrm{TM}} \text {, } \\
\text { diam. } 200 \mu \mathrm{m})\end{array}$ & $\begin{array}{l}0.11: 0.12: 0.005: 1 \\
\text { in 50 vol\% EC }\end{array}$ & 50.225 .2 & 0.666 & $\begin{array}{l}157 \\
\text { grafted } \\
\text { chains } \\
\text { broken }\end{array}$ & $\mathrm{N} / \mathrm{A}$ & $\mathrm{N} / \mathrm{A}$ \\
\hline
\end{tabular}

\section{Fiber spinning and ATRP from commercial CPE}

As it is described in previous sections, halide-containing polymer can initiate ATRP. Among them, one of the readily available commercial resins is chlorinated polyethylene (CPE). CPE is widely used as a thermoplastic elastomer, rubber, and a modifier for resin (PE, poly(vinylchloride) and poly(acrylonitrile-co-butadiene-co-styrene) $(\mathrm{ABS}))$ because of its excellent resistance properties against heat and oil, as well as fire, chemicals, and weather. ${ }^{1}$ We have contacted several companies, which produce $\mathrm{CPE}$, however, no company manufactures fibers of CPE resins. Since it was not available as a fiber form, we requested $\mathrm{CPE}$ resins from companies and performed fiber spinning using our spinning device (Fig. 8). The properties of CPE resin received are summarized in Table 5.

\footnotetext{
${ }^{1}$ DARKEN: chlorinated polyethylene brochure, DAISO Co. LTD
}

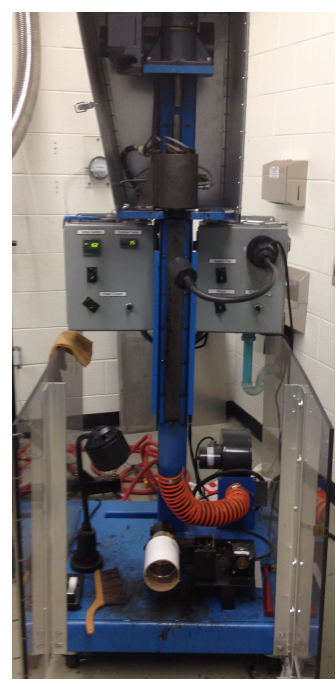

Fig. 8 Fiber spinning device. 
Table 5 Properties of CPE received from DAISO Co. LTD

\begin{tabular}{lrrrrr}
\hline & $\begin{array}{c}\mathrm{Cl} \\
(\mathrm{wt} \%)\end{array}$ & $\begin{array}{c}\mathrm{Cl} \text { per } \\
\text { repeat unit }\end{array}$ & $\begin{array}{c}\mathrm{T}_{\mathrm{g}} \\
\left({ }^{\circ} \mathrm{C}\right)\end{array}$ & $\begin{array}{c}\mathrm{T}_{\mathrm{m}} \\
\left({ }^{\circ} \mathrm{C}\right)\end{array}$ & $\begin{array}{c}\% \\
\text { crystallinity }\end{array}$ \\
\hline $1030 \mathrm{~L}$ & 30.2 & 2.92 & -17 & 120 & 0.31 \\
$1035 \mathrm{X}$ & 33.3 & 2.53 & -15 & 119 & 0.16 \\
$1035 \mathrm{UHX}$ & 33.4 & 2.52 & -17 & 117 & 0.08 \\
1040 & 40 & 1.90 & -6 & 76,130 & 0.20 \\
\hline
\end{tabular}

$\mathrm{T}_{\mathrm{g}}, \mathrm{T}_{\mathrm{m}}$, and \% crystallinity were measured using differential scanning calorimetry (DSC).

The initial plan was to obtain fibers with different degree of chlorination (30-40 wt\%), so that the grafting density can be tuned. We expected to obtain decent fibers of CPE, however, they all turned out to be very rubbery fibers without enough mechanical strength. The properties were further confirmed using differential scanning calorimetry (DSC), shown in Table 5. Polyethyelene typically has $40-90 \%$ crystallinity (e.g.; low crystallinity corresponds to low density polyethylene and high crystallinity corresponds to high density polyethylene), which gives high tenacity in a fiber form. These CPE resins lost crystallinity due to chlorination. The amorphous polymer without crystallinity would give rubbery polymers. Our results explain why companies do not manufacture fibers of CPE. The direct spinning of CPE resins to obtain CPE fibers does not give mechanically robust fibers.

Thus, fiber spinning of blend of CPE and HDPE (high density polyethylene) was performed to improve the mechanical property of the fibers. HDPE is typically spun to PE fibers, thus, the addition of HDPE is expected to provide mechanical integrity. First, HDPE and CPE have to be mixed using compounders and then, the mixed resin can be spun to fibers. Two CPE resins were chosen for this experiment, the $1040(40 \mathrm{wt} \% \mathrm{Cl})$ and the WEIPREN CPE $(25 \mathrm{wt} \%$ $\mathrm{Cl}$, LIANDA CO. Ltd.). HDPE (75 wt\%) and CPE (25wt\%) were melt-mixed using a compounder, and the mixed resin was spun to fibers. The dye was clogged during spinning of HDPE-1040 mixture and the fiber spinning was not further attempted. HDPE-WEIPREN CPE, however, was successfully spun to fibers, and the obtained fibers showed mechanically robust properties, similar to those of typical polyethylene fibers.

The HDPE-CPE spun fiber used was made from the mixture of $1.5 \mathrm{~g}$ HDPE and $0.4 \mathrm{~g}$ CPE (WEIPREN, $25 \mathrm{wt} \% \mathrm{Cl}$ ), resulting in the overall $5.3 \mathrm{wt} \% \mathrm{Cl}$, corresponding to the empirical formula $\mathrm{CH}_{2} \mathrm{Cl}_{0.06}$. The ${ }^{13} \mathrm{C} \mathrm{CP} / \mathrm{MAS}$ spectrum of this HDPE-CPE spun fiber reveals the presence of monochlorinated ATRP initiation sites $(65 \mathrm{ppm})$ in a small amount (Fig. 9). No signal from a more active ATRP initiation site, dichlorinated carbon, normally expected around $98 \mathrm{ppm}$, was observed.

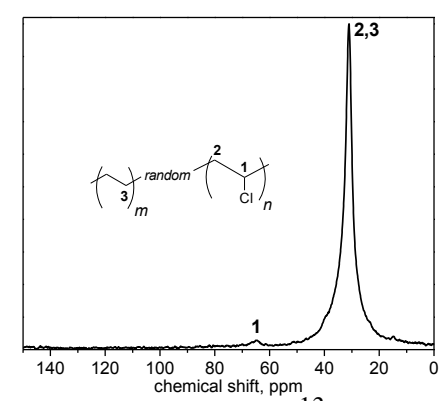

Fig. 9 100-MHz ${ }^{13} \mathrm{C} \mathrm{CP} / \mathrm{MAS}$ spectrum of HDPE-CPE fiber (spinning speed $7.5 \mathrm{kHz}$ ). 
Simultaneous ATRP grafting of AN and $t$ BA (496 AN:309 $t \mathrm{BA}: 1 \quad \mathrm{CuCl}: 1.2$ $\mathrm{Me}_{6} \mathrm{TREN}: 0.05 \mathrm{CuCl}_{2}: 1 \mathrm{RCl}$, in $50 \mathrm{vol} \% \mathrm{EC}, 65^{\circ} \mathrm{C}, 24 \mathrm{~h}$ ) yielded only $36 \%$ d.g. This d.g. was much lower than those obtained from all other trunk fibers in our study. This is likely due to the very low amount of ATRP initiation sites, as well as the lack of more active initiation sites (i.e., dichlorinated carbons). After amidoximation and $\mathrm{KOH}$ treatment $\left(80^{\circ} \mathrm{C}, 3 \mathrm{~h}\right)$, this adsorbent fiber showed a low U adsorption capacity of $20.3 \mathrm{~g} / \mathrm{kg}$, consistent with its low d.g. This is the lowest $U$ adsorption capacity observed among ATRP trunk fibers studied in our group. Due to this preliminary result, no further work was planned for this trunk fiber.

\section{Conclusions}

The following conclusions can be drawn from this study:

- ATRP, without RIGP, was successfully performed on several novel trunk fibers, and those fibers showed good U adsorption. These novel trunk fibers include CPP (hollow-gear and round), CPE (hollow-gear and round), PVDF and PVDC.

- Novel-functionalization (chlorination) on fiber substrates to provide halide functionality (ATRP initiation sites) was successfully performed. New trunk fibers containing ATRP active alkyl chlorides were chemically grafted via ATRP grafting of AN and $t$ BA.

- Among novel trunk fibers tested, the following are listed in order of $U$ adsorption capacities: sun $3 \mathrm{~h}$ CPP $>$ sun $2 \mathrm{~h}$ CPP $>$ UV CPP $\sim$ UV CPE, PVDC, HDPE-CPE.

- PVDF was not active as an ATRP initiator which, as expected, indicates that fluorine cannot initiate ATRP. For the choices of ATRP initiation sites, halide functionality such as chloride and bromide need to be used.

- PVDC showed the highest grafting yields; however, grafted fibers were easily broken off from trunk fibers, even at low d.g., resulting in lower $U$ adsorption capacities than expected. This result indicates that we need to consider, not only grafting chemistry via ATRP, but also the mechanical properties upon grafting, although PVDC was a highly active ATRP initiator.

- Hollow-gear PP (manufactured by Hills) could not be chlorinated in high degree and was not used as an ATRP initiator. It is not clear why since the regular PP fiber can be chlorinated.

- Chlorinated hollow-gear PE showed a promising result among new trunk fibers studied. Since ORNL has a lot of experiences with hollow-gear PE (38H series, AF1 series, etc.) and this finding may be helpful when we compare the difference between ATRP and RIGP.

- HDPE-CPE did not contain enough active initiation sites. Grafting yield and U adsorption capacity were low. To keep the mechanical integrity of the trunk fibers, more initiation sites cannot be incorporated in this approach.

- Grafted Rhovyl ${ }^{\mathrm{TM}}$ (PVC-co-CPVC) fiber (our current standard fiber for ATRP) still showed the highest $\mathrm{U}$ adsorption capacities compared to tested trunk fibers in this task.

\section{References}

1. $\quad$ Mukherjee, A. K.; Patri, M.; Mohan, A. J. Polym. Eng. 1991, 10, 1-3, 1-19.

2. $\quad$ Benedikt, G. M.; Goodall, B. L.; Rhodes, L. F.; Kemball, A. C. Macromol. Symp. 1994, 86, 65-75.

3. Tan, K. L.; Li, C. X.; Lu, Y. Z.; Wang, Z. H. Polym. Eng. Sci. 2009, 49 , 8, 1587-1593.

4. Saito, T.; Brown, S.; Chatterjee, S.; Kim, J.; Tsouris, C.; Mayes, R. T.; Kuo, L.-J.; Gill, G.; Oyola, Y.; Janke, C. J.; Dai, S. J. Mater. Chem. A 2014, 2, 14674-14681. 